\title{
Identifying the Zheng in psoriatic patients based on latent class analysis of traditional Chinese medicine symptoms and signs
}

Xuesong Yang ${ }^{1}$, Virasakdi Chongsuvivatwong ${ }^{2}$, Sanguan Lerkiatbundit ${ }^{3}$, Jianzhou Ye ${ }^{1}$, Xiaoyong Ouyang ${ }^{1}$, Enpin Yang ${ }^{1}$ and Hutcha Sriplung ${ }^{2^{*}}$

\begin{abstract}
Background: There are approximately five Zhengs reported in psoriatic patients. Systematic data collection and proper analysis for the classification of psoriasis have been lacking. This study aims to cluster the Zhengs in psoriatic patients based on the application of a checklist of traditional Chinese medicine (TCM) symptoms and signs followed by latent class analysis (LCA).

Methods: A cross-sectional study of 507 psoriatic patients aged above 10 years was performed in Yunnan Provincial Hospital of TCM and the First Affiliated Hospital of Kunming Medicine University from October 2010 to September 2011 using a TCM symptoms and signs checklist obtained from 16 TCM experts by the Delphi technique. LCA was applied to obtain the best fitted model for clustering of symptoms and signs that can be interpreted as underlying Zhengs of psoriasis.

Results: The LCA identified three Zhengs: dampness-heat Zheng (35.1\%); blood heat Zheng (34.7\%); and yin deficiency and blood dryness Zheng (30.2\%). The first Zheng was associated with winter, the second with male sex, old age, smoking, and drinking alcohol, and the third with outpatient status, which reflected a mild disease course.

Conclusions: In this study, 507 psoriasis patients were clustered into three Zhengs, which had different associated factors.
\end{abstract}

\section{Introduction}

Psoriasis is a chronic life-long inflammatory disease that primarily affects the skin [1], and has a prevalence in the general population that ranges between $0.6 \%$ and $4.8 \%$ [2]. The disease is associated with an increased risk of metabolic syndrome, diabetes, hypertension, and cardiovascular mortality [3,4], suicidality [5], depression and anxiety [6], and low employment, income, and quality of life [7]. In the United States, psoriasis was estimated to have incurred 6.7 billion United States dollars (USD) of direct costs and 4.5 billion USD of indirect costs, including administration, personnel, and security costs, in 2010 [8]. The total annual costs for psoriasis treatment amounted to approximately 350-510 million USD in Switzerland in 2004 [9].

\footnotetext{
*Correspondence: hutcha.s@psu.ac.th

${ }^{2}$ Epidemiology Unit, Faculty of Medicine, Prince of Songkla University, Hat Yai, Songkhla 90110, Thailand

Full list of author information is available at the end of the article
}

The diagnosis of psoriasis in traditional Chinese medicine (TCM) was first recorded by Cao Yuan Fang in the Sui Dynasty (AD 610) as "dry ringworm" (ganxuan), with descriptions of the symptoms, signs, and pathogenic mechanism of psoriasis, in his book "Zhu Bing Yuan Houlun" [10]. In the Qing dynasty (AD 1665), psoriasis was named "white mange" (bai bi) in "Wai Ke Da Cheng".

According to the textbook entitled "Surgery of Traditional Chinese Medicine" [11], psoriasis is attributed to long stagnation of pathogenic wind and heat resulting from exposure to exogenous wind, cold, or heat, or from internal factors of emotional injury and stagnation of $q i$, and obstruction of the meridians and collaterals that leads to qi stagnation and blood stasis. If the meridians and collaterals are obstructed by exogenous wind, dampness, and heat toxin, the condition can also affect the joints.

\section{Biomed Central}


Unlike Western medicine, TCM does not emphasize disease classification, but instead classifies a patient by their Zheng (TCM syndrome or pattern). Consequently, two patients with the same disease may be classified into different Zhengs according to their symptoms and signs, and different treatment protocols will be given according to the identified Zhengs. However, two patients suffering from different diseases may have the same pathologic Zheng and require the same treatment protocol.

Studies on psoriasis in TCM have reported approximately five different Zheng classifications. Zhang et al. [12] and Wang et al. [13] classified blood heat and blood dryness as the two main Zheng classes. Zhang et al. [11] found blood stasis as the third Zheng, while Wang et al. [13] found dampness heat and blood stasis as the third and fourth Zhengs. Wu et al. [14] identified yin deficiency as one of the Zhengs in psoriasis. Zhang et al. [12], Wang et al. [12], and Wu et al. [14] classified blood dryness as one Zheng class of psoriasis. However, Wang et al. and Wu et al. disagreed on the other classes. Li et al. [15] used the five viscera to classify psoriasis Zhengs, while Li [16] based his classification on wind dryness with three different Zheng combinations. All of these studies were descriptive and did not report statistical analyses of clusters or classes.

Amidst the variation in classifications, a national diagnosis standard for the classification of psoriasis was announced in 1994 [17], and it has not been updated since. The standard classification includes three Zhengs: (1) wind heat and blood dryness; (2) wind and dryness due to blood deficiency; and (3) blood stasis. Most of the previous studies have been based on expert opinions, without any study protocols. There were also inadequate attempts to classify the patients.

A systematic checklist [18] was developed for reproducible data collection and statistical analysis. The patients could be further clustered and assigned to groups of Zhengs.

Latent class analysis (LCA) is a statistical method for identifying unmeasured class memberships among subjects using categorical or continuous observed variables, or both [18]. LCA attempts to achieve data reduction by classifying the subjects into one of $\mathrm{K}$ unobserved classes based on observed data, where $\mathrm{K}$ is fixed and known. Such latent classes are identified by their relationships with the observed variables [19] for disease subtypes or diagnostic subcategories.

Thus, LCA would be applicable to clustering of psoriasis in TCM. This study aims to perform an LCA to cluster psoriatic patients into various Zheng groups based on the application of a checklist of TCM symptoms and signs.

\section{Methods}

\section{Study design and setting}

A cross-sectional study was carried out at Yunnan Provincial Hospital of Traditional Chinese Medicine and the First Affiliated Hospital of Kunming Medicine University. This study was performed during a 12-month period from October 2010 to September 2011, after receiving approval from the Ethical Committee Board of the Faculty of Medicine, Prince of Songkla University.

\section{Study subjects}

The psoriatic subjects were aged over 10 years, and recruited from inpatients and outpatients of the Dermatology and Rheumatism Departments of the two hospitals. The sample size was initially set at 500 [20] to fit a checklist of 96 items (the development of the checklist is described below). The exclusion criteria were patients having communication difficulties, severe psychiatric disorders, or cognitive problems.

Patients with severe dysfunction of organs and those receiving retinoid, methotrexate, or glucocorticosteroid treatments within 1 month were also excluded, because their symptoms and signs would be altered by the dysfunctions and disease treatments.

\section{The TCM standard checklist of symptoms and signs of psoriasis}

The process of the checklist development was described in detail in a previous article [21]. Briefly, a three-round Delphi study was conducted by 16 experts (seven from Beijing and nine from Yunnan) between July and September 2010. A draft checklist was created by literature review of articles and textbooks. In the end, there were 96 items (eight domains) of psoriatic symptoms and signs in TCM in the checklist. The eight domains included (1) color, (2) shape, (3) type of skin lesion, (4) associated factors, (5) physical expression, (6) tongue substance and tongue coating, (7) pulse, and (8) living environment. The psoriasis symptom items were rated "yes" or "no". Notes on symptoms and signs and pulse palpation were completed by the first author (XY).

\section{Patient recruitment}

The selected psoriatic patients were informed of the objectives and search procedures of the study and signed consent forms themselves or through their guardians if they were adolescents. The TCM checklist of symptoms and signs was completed. All of the patients had a confirmed diagnosis by exhibiting typical skin lesions and other physical signs. A skin pathological examination confirmed the cases in doubt. The color and texture of the skin lesion and tongue were observed under ambient light in the examination room. Personal health behaviors, such 
as smoking, drinking, and associated diseases, were assessed during an interview. Hypertension was verified using a mercury sphygmomanometer and a history of anti-hypertensive use was taken. Diabetes mellitus was evaluated by history alone.

\section{Statistical methods}

Descriptive statistics were used to summarize the characteristics of the patients regarding their symptoms and signs. LCA was used to classify the subjects based on the variables of symptoms and signs in TCM collected in the checklist. The patients were allocated to classes based on the maximum estimate of posterior probability of cluster membership. Model solutions were evaluated using the Bayesian Information Criterion (BIC), which has been shown to be a robust indicator of the preferred $\mathrm{K}$ class solution [22]. Lower BIC values indicated a better model fit. The Vuong-Lo-Mendell-Rubin likelihood ratio (VLMR-LR) test goodness-of-fit index, which considers parsimony, was used to compare the null hypothesis of k-1 clusters with alternative clusters [23]. The significance tests used to compare the characteristics among the classes were the chi-square test for categorical variables and the Kruskal-Wallis test for continuous variables.

R 2.12.2 software (R Foundation, Austria) [24] was used to perform the descriptive statistics. Mplus software 5.0 (Muthén \& Muthén, USA) [25] was used for the LCA. A class was defined as the group into which patients were identified by the prominent probability in their symptom and sign manifestations present in the checklist [18].

The composition of each class (and class name) was independently evaluated by five independent dermatology experts. Their opinions were then cross-checked. Any inconsistent opinions were settled by discussion among these experts to determine the final Zheng classes.

\section{Results}

Five hundred and seven patients were recruited. Their characteristics are summarized in Table 1 . The percentage of males was slightly higher than that of females. Most of the patients were Han in ethnicity, and $83.4 \%$ were outpatients. The patient ages ranged from 11.5 to 74.8 years. High school as the highest education level accounted for $50.3 \%$. The patients had varied duration and severity of disease, and the majority were psoriasis vulgaris cases. The median duration of disease was 5.6 years, and the interquartile range was 2.0 to 11.9 years. More than half of the patients had no reported associated diseases. However, hypertension (8.1\%), diabetes (3.4\%), and gastrointestinal diseases $(8.9 \%)$ were not uncommon.
Table 1 Demographic, social, and clinical characteristics of the $\mathbf{5 0 7}$ patients

\begin{tabular}{|c|c|c|}
\hline Variable & $\begin{array}{l}\text { Number } \\
(n=507)\end{array}$ & Percentage \\
\hline \multicolumn{3}{|l|}{ Sex } \\
\hline Male & 294 & 58.0 \\
\hline \multicolumn{3}{|l|}{ Ethnicity } \\
\hline Han & 462 & 91.1 \\
\hline Others & 45 & 8.9 \\
\hline Age (mean \pm standard deviation) & $37.0 \pm 15.8$ & - \\
\hline \multicolumn{3}{|l|}{ Type of psoriasis } \\
\hline Vulgaris & 461 & 90.9 \\
\hline Erythrodermic & 17 & 3.4 \\
\hline Pustular & 16 & 3.0 \\
\hline Arthritic & 13 & 2.6 \\
\hline \multicolumn{3}{|l|}{ Marital status } \\
\hline Single & 179 & 35.3 \\
\hline Ever-married & 328 & 64.7 \\
\hline \multicolumn{3}{|l|}{ Associated diseases } \\
\hline Hypertension & 41 & 8.1 \\
\hline Coronary heart disease & 8 & 1.6 \\
\hline Diabeties & 17 & 3.4 \\
\hline Hepatitis & 9 & 1.8 \\
\hline Gastrointestinal diseases & 45 & 8.9 \\
\hline Other diseases & 113 & 22.3 \\
\hline No disease & 274 & 53.9 \\
\hline Psoriasis duration (years), Median (IQR) & $5.6(2.0,11.9)$ & - \\
\hline Progression phase & 441 & 87.0 \\
\hline Stable phase & 49 & 9.7 \\
\hline Remission phase & 17 & 3.4 \\
\hline Smoking & 162 & 32.0 \\
\hline Drinking & 133 & 26.2 \\
\hline \multicolumn{3}{|l|}{ Season of exacerbation } \\
\hline Spring & 109 & 21.5 \\
\hline Summer & 97 & 19.1 \\
\hline Autumn & 115 & 22.7 \\
\hline Winter & 186 & 36.7 \\
\hline
\end{tabular}

\section{Number of classes based on the LCA}

Items on types and shapes of skin lesions were excluded from the LCA because they represented the expressions of the psoriatic diseases caused by groups of Zhengs, and were not considered to be symptoms and signs of the underlying Zheng. Items occurring in less than $2 \%$ of the patients were also excluded because they were negligible to clustering.

After the LCA, 50 items of symptoms and signs were retained in the models. Table 2 shows the values for the 
Table 2 Results of the latent class analysis: model fit indices comparing different class solutions

\begin{tabular}{lllll}
\hline Index & \multicolumn{4}{l}{ Number of class (k) } \\
\cline { 2 - 5 } & $\mathbf{2}$ & $\mathbf{3}^{*}$ & $\mathbf{4}$ & $\mathbf{5}$ \\
\hline BIC & 31936 & 31788 & 31987 & 31904 \\
VLMR LR test (p-value) & 0.0004 & 0.037 & 0.7025 & 0.9799 \\
Proportion of each class & $47.3 \%$ & $35.1 \%$ & $24.1 \%$ & $21.9 \%$ \\
& $52.7 \%$ & $34.7 \%$ & $21.1 \%$ & $16.0 \%$ \\
& & $30.2 \%$ & $21.9 \%$ & $31.4 \%$ \\
& & & $32.9 \%$ & $9.1 \%$ \\
& & & & $21.6 \%$
\end{tabular}

*Best fitted model.

BIC and VLMR-LR tests for models with various numbers of classes and their distributions. The model with three classes gave the lowest BIC, and was better than the model with two classes (VLMR p-value $=0.037)$. The model with four classes was not significant $(\mathrm{p}=0.70)$. Therefore, the three-class model was chosen as the best fitted model. Using this model, the percentages of subjects falling into classes 1,2 , and 3 were $35.1 \%, 34.7 \%$, and $30.2 \%$, respectively.

Within each class, items with probability higher than 0.6 were sorted according to the four examination methods of TCM (inspection, auscultation and olfaction, interrogation, and palpation). Six symptoms and signs were common to all three classes (white coating, predilection heavy and greasy, intermittent itching, string pulse, dry taste and thirst, and bluish sublingual varicose veins).

All five independent TCM dermatology experts agreed to these three Zhengs. Based on the high frequencies of various symptoms and signs (marked by asterisks in Table 3) in each Zheng, the experts concluded that class 1 was dominated by dampness-heat Zheng, class 2 by blood heat Zheng, and class 3 by a combined yin deficiency and blood dryness Zheng.

The latent clusters obtained in this study were groups of subsets of latent variables that usually occurred together. For example, class 1 in Table 3 consists of a group of variables that can be interpreted as dampness (flabby

Table 3 Prominent items (probability higher than 0.6 ) in each class

\begin{tabular}{|c|c|c|c|}
\hline \multirow[t]{2}{*}{ Diagnosis method } & \multirow{2}{*}{$\begin{array}{l}\text { Class } 1(n=178) \\
\text { Dampness-heat Zheng }\end{array}$} & \multirow{2}{*}{$\begin{array}{l}\text { Class } 2(n=176) \\
\text { Blood heat Zheng }\end{array}$} & \multirow{2}{*}{$\begin{array}{l}\text { Class } 3(n=153) \\
\text { Yin deficiency and blood dryness Zheng }\end{array}$} \\
\hline & & & \\
\hline \multirow[t]{13}{*}{ Inspection } & \multirow[t]{3}{*}{ Darker skin color* (73.1\%) } & Garnet skin color* (62.3\%) & \multirow[t]{3}{*}{ Pink skin color* $(92.2 \%)$} \\
\hline & & Darker skin color (60.2\%) & \\
\hline & & Sore throat* $(87.6 \%)$ & \\
\hline & \multirow[t]{3}{*}{ Sore throat (76.4\%) } & Pharyngeal wall & \multirow[t]{3}{*}{-} \\
\hline & & Follicular* (67.8\%) & \\
\hline & & Fissured tongue (63.3\%) & \\
\hline & Red tongue* $(60.7 \%)$ & \multirow[t]{6}{*}{ Crimson tongue* $(77.0 \%)$} & Red tongue* (61.5\%) \\
\hline & Flabby tongue (62.9\%) & & Red tip of tongue (65.1\%) \\
\hline & Teeth-printed tongue (65.7\%) & & Thin tongue* $(66.7 \%)$ \\
\hline & Yellow tongue coating* (72.7\%) & & Thin tongue coating* $(81.5 \%)$ \\
\hline & Thick tongue coating*(80.6\%) & & \multirow[t]{2}{*}{ Less tongue coating* $(92.3 \%)$} \\
\hline & Greasy coating* $(98.5 \%)$ & & \\
\hline & - & Scanty dark urine* $(67.9 \%)$ & - \\
\hline Auscultation and olfaction & Fetid breath (62.5\%) & - & - \\
\hline \multirow[t]{8}{*}{ Interrogation } & Predilection pungent (72.0\%) & - & Predilection pungent (77.2\%) \\
\hline & Attacking on depression and morose (71.8\%) & - & Predilection cold and raw food (62.3\%) \\
\hline & - & - & Anxiety and irritability* (73.5\%) \\
\hline & \multirow[t]{2}{*}{-} & & Frequent dreams (65.8\%) \\
\hline & & - & Constipation* (65.7\%) \\
\hline & - & - & Aggravated after coldness (72.3\%) \\
\hline & - & - & Slight itching (61.5\%) \\
\hline & - & - & Overexertion* (61.8\%) \\
\hline \multirow[t]{2}{*}{ Palpation } & Slippery pulse* (68.9\%) & - & Thready pulse* (64.5\%) \\
\hline & - & - & Rapid pulse* (66.8\%) \\
\hline
\end{tabular}

*Essential item predominating in each Zheng class. 
tongue, teeth-printed tongue, yellow, thick, and greasy tongue coating, and slippery pulse) and another group representing heat (darker skin color, sore throat, red tongue, fetid breath, and predilection pungent). Patients in this class manifest both Zhengs together and, in such cases, dampness-heat Zheng is used to name this class. A thorough discussion of LCA in TCM and interpretation of latent clusters was performed by Zhang et al. [26]. Seven symptoms and signs (garnet, darker skin color, sore throat, pharyngeal wall follicular, fissured tongue, crimson tongue, and scanty dark urine) were present in the second class with mean invasion of the blood phase by pathologic heat. Blood heat Zheng defines this cluster. Even though this cluster reflects heat like the first cluster, the symptoms and signs of heat were more prominent and not concomitant with dampness Zheng. In fact, dampness could lessen the expression of heat Zheng in the first class, but the patients still suffered from both dampness and heat Zhengs.
Eight symptoms and signs representing yin deficiency (red tongue, thin tongue, red tip of tongue, thin tongue coating, predilection cold and raw food, anxiety and irritability, frequent dreams, and rapid pulse) were involved in the third cluster. In the third cluster, four symptoms and signs (pink skin color, less tongue coating, overexertion, and aggravated after coldness) could be interpreted as blood dryness Zheng. There are four symptoms and signs (constipation, slight itching, thready pulse, and less tongue coating) in the third cluster, which are known to occur in combined yin deficiency and blood dryness Zheng.

\section{Characteristics of psoriatic patients among the three classes}

The characteristics of the psoriatic patients among the three classes are summarized in Table 4. Winter was the worst season for all three Zheng classes Exacerbations of lesions in winter were most pronounced in dampness-heat

Table 4 Characteristics of the psoriatic patients among the three classes

\begin{tabular}{|c|c|c|c|c|}
\hline \multirow[t]{2}{*}{ Variable } & \multirow{2}{*}{$\begin{array}{l}\text { Class } 1(\mathrm{n}=178) \\
\text { Dampness-heat Zheng }\end{array}$} & \multirow{2}{*}{$\frac{\text { Class } 2(n=176)}{\text { Blood heat Zheng }}$} & \multirow{2}{*}{$\begin{array}{l}\text { Class } 3(n=153) \\
\text { Yin deficiency and blood dryness Zheng }\end{array}$} & \multirow[t]{2}{*}{$P$ value* } \\
\hline & & & & \\
\hline \multicolumn{5}{|l|}{ Gender } \\
\hline Male & $97(54.5)$ & $129(73.3)$ & $70(45.8)$ & \multirow[t]{2}{*}{$<0.01$} \\
\hline Female & $81(45.5)$ & $47(26.7)$ & $83(54.2)$ & \\
\hline \multicolumn{5}{|l|}{ Seasons } \\
\hline Spring & $28(15.7)$ & $41(23.3)$ & $40(26.1)$ & \multirow[t]{4}{*}{$0.045^{* *}$} \\
\hline Summer & $36(20.2)$ & $32(18.2)$ & $29(18.9)$ & \\
\hline Autumn & $39(22.0)$ & $35(19.9)$ & $41(26.8)$ & \\
\hline Winter & $75(41.1)$ & $68(38.6)$ & $43(28.1)$ & \\
\hline Age, Median (IQR) & $34.5(24.2,47.3)$ & $39.9(28,53.6)$ & $32.2(22.4,40.7)$ & $<0.001$ \\
\hline \multicolumn{5}{|l|}{ Ethnicity } \\
\hline Han & $165(92.7)$ & $159(90.3)$ & $137(89.5)$ & \multirow[t]{2}{*}{0.667} \\
\hline Others & $13(7.3)$ & $17(9.7)$ & $16(10.5)$ & \\
\hline \multicolumn{5}{|l|}{ Type of patient } \\
\hline In-patient & 47 (26.4) & $33(18.8)$ & $5(3.3)$ & \multirow[t]{2}{*}{$<0.001$} \\
\hline Out-patient & $131(77.6)$ & $143(81.2)$ & $148(96.7)$ & \\
\hline \multicolumn{5}{|l|}{ Smoking } \\
\hline Yes & 49 (27.6) & $79(44.9)$ & $34(22.2)$ & \multirow[t]{2}{*}{$<0.001$} \\
\hline No & $129(72.4)$ & $97(55.1)$ & $119(77.8)$ & \\
\hline \multicolumn{5}{|l|}{ Drinking } \\
\hline Yes & $33(18.5)$ & $65(36.9)$ & $35(22.9)$ & \multirow[t]{2}{*}{0.003} \\
\hline No & $145(81.5)$ & $111(63.1)$ & $118(77.1)$ & \\
\hline \multicolumn{5}{|l|}{ Associated diseases } \\
\hline Hypertension & $15(8.4)$ & $19(10.8)$ & $7(4.6)$ & 0.065 \\
\hline Gastrointestinal disease & $8(4.5)$ & $17(9.7)$ & $20(13.1)$ & 0.074 \\
\hline Diabetes mellitus & $7(3.9)$ & $6(3.4)$ & $4(2.6)$ & 0.610 \\
\hline
\end{tabular}


Zheng. However, patients with yin deficiency and blood dryness Zheng were likely to have lesions all year round with a better disease course in summer, while those with dampness-heat and blood heat Zhengs tended to have lesions that would subside when the temperature increased. The blood heat Zheng class had the highest proportion of males and the highest median age. The patients classified as having yin deficiency and blood dryness Zheng were less likely to be hospitalized. Smoking and alcohol drinking were more prevalent in the blood heat Zheng group. The associations between psoriasis class and other diseases, such as hypertension and gastrointestinal disease, were not strong with P-values of 0.06 and 0.07 , respectively.

\section{Discussion}

This study classified psoriatic patients into three groups, based on the three main Zhengs they suffered, i.e., "dampness-heat", "blood heat", and "yin deficiency and blood dryness". Nevertheless, there were six miscellaneous symptoms and signs common to all three Zheng classes without specificity for any one class, namely (1) predilection for a heavy or greasy diet, (2) white tongue coating, (3) bluish sublingual varicose veins, (4) intermittent itching, (5) dry taste and thirst, and (6) string pulse.

Zhang et al. [26] suggested latent tree models and diagnosis in TCM. This study is the first to use a standard checklist of symptoms and signs and a proper statistical analysis to investigate the Zhengs in psoriasis disease. There is known to be an assumption of mutual independency for the manifested variables for LCA. However, this assumption is often violated to some extent, especially when there are a large number of variables [27].

In contrast to Zhang et al. [12] and Wang et al. [13], in which statistical techniques for clustering of symptoms and signs were not used, our results suggested that blood dryness should be classified together with yin deficiency. Wu et al. [14] also identified yin deficiency as one of the Zhengs in psoriasis, but this was combined with other Zhengs, and not with blood dryness as found in our study. Zhang et al. [12], Wang et al. [13], and Wu et al. [14] classified blood dryness as one Zheng class of psoriasis, similar to our study.

The LCA employed a model-based clustering approach, placing patients experiencing similar patterns of symptoms and signs into the same class [28]. Different findings in Zheng may be caused by (1) researchers using different checklists, (2) clinicians having different training and experience, and (3) variation in epidemiological patterns of Zheng arising through variation in the population characteristics, geography, and time periods. Based on the theory of TCM, in which personal constitutions are the foundation of disease development, there might be some variation in the Zheng diagnosis among populations living in different geographic regions and climates $[29,30]$.
Based on TCM theory, Zheng was associated with the seasons. Cui et al. [31] reported seasonal diversity of TCM Zhengs in 609 cases of acute diarrhea. Tan et al. [32] reported four Zhengs in 698 hypertension cases. The occurrence of liver fire flaming-up Zheng was common in spring (102 cases) and relatively rare in summer (16 cases). The other three Zhengs included yin deficiency and yang excess (92 cases), phlegm-dampness accumulation (82 cases), and yin-yang deficiency (64 cases). Our study showed that the Zhengs in psoriasis were associated with seasons. Dampness-heat Zheng was predominant in summer (48.9\%) and autumn (30.8\%), and cold dampness Zheng was dominant in winter (53.6\%) and spring (35.6\%). Guo et al. [33] reported the onset and exacerbation of psoriasis with liver gallbladder dampness-heat Zheng associated with spring.

Our results showed different Zhengs from the previous studies, which might arise through differences in geography. Geographic influence on Zheng has been known in studies on irritable bowel syndrome, showing clear differences between patients in the south of the five ridges area and those in the northeast area of China [34]. For viral hepatitis, TCM doctors in the southern and northern parts of China used different theories [35]. Dampness-heat Zheng is always associated with spleen, stomach, liver, and gallbladder [36]. In previous studies, dampness-heat Zheng was commonly found in pustular psoriasis and psoriatic arthritis [37,38]. However, our patients were mainly psoriasis vulgaris cases, and this association could not be tested. Dampness-heat Zheng was common in our study in Yunnan, where the diet generally includes spicy, heavy, greasy, and pungent foods, and such a diet might cause dampness-heat [39]. However, dampness-heat was reported to be common in inner-Mongolia (16\% were dampness-heat of spleen and stomach) by Li et al. [15] and Beijing by Wang et al. [13].

Blood heat was the second most common Zheng in this study. The mechanism of blood heat has been described as invasion of heat into the blood path resulting in disease [11]. Usually, rapid and string pulse is the manifestation of blood heat. However, the character of the pulse was not classified in class 2 (blood heat Zheng) because the LCA detected string pulse in all three classes and rapid pulse was more predominant in class 3 (yin deficiency and blood dryness) than in class 2 . Although both pulse characteristics were common to blood heat Zheng, they were not useful for the Zheng class differentiation. Blood heat Zheng was mentioned in the national criteria for Zheng diagnosis of psoriasis and also reported in $53.8 \%$ of patients by Zhang et al. [12]; in $36.7 \%$ by Wang et al. [13], and reported as heart blood heat by Li et al. [15] (25.0\%) and by Li et al. [16] as combinedwind dryness and blood heat. Blood heat Zheng was the most commonly reported Zheng in psoriasis studies in China. 
The combined yin deficiency and blood dryness Zheng was the third group in our list. These two factors might interact and influence the psoriasis course in the long term. This class was a combination of symptoms and signs of the two subgroups of Zhengs. Red and thin tongue, red tip of tongue, anxiety and irritability, frequent dreams, predilection cold and raw, and thready and rapid pulse are symptoms and signs of yin deficiency [40]. Liver kidney yin deficiency was reported by Wu et al. [14] (21 of 200 cases). Another subgroup of symptoms and signs of Zheng consisting of pink color, thin and less tongue coating, and thready pulse are the main manifestations of blood dryness [41]. Blood dryness Zheng has been more commonly reported (27.4\%, Zhang et al. [12]; 6.0\%, Wu et al. [14]; $36.7 \%$, Wang et al. [13]) than yin deficiency Zheng.

There were six symptoms and signs that could not be assigned to any one of the three Zhengs. These were common to all three classes, and their significance and underlying pathologic mechanisms require further investigation.

Unlike previous reports on the classification of psoriasis, which were based on single or only a few experts' opinions, ours was based on a consensus checklist, systematic data collection for a large sample size, reliable statistics, and final agreement on the Zheng clustering among 16 experts from different hospitals.

To our knowledge, there has been no established standard for Zheng classification in TCM for psoriasis. Even though our clustering reached expert consensus, the level of accuracy of this clustering could not be assessed because variation in the Zheng classification might occur in different geographic and climate environments and populations. Thus, our results need to be verified in different settings in China. Furthermore, this study was carried out among moderate to severe psoriasis patients who attended specialized hospitals. Studies among mildly affected patients might elucidate a wider spectrum of psoriasis Zheng clustering.

\section{Conclusions}

In this study, 507 psoriasis patients could be clustered into three Zhengs, which had different associated factors. The first Zheng, dampness-heat, was associated with exacerbation in winter, the second, blood heat, was associated with male sex, old age, smoking, and alcohol drinking, and the third, Yin deficiency and blood dryness, was associated with a mild clinical course without necessity for hospital admission.

\section{Competing interests}

The authors declare that they have no competing interests.

\section{Authors' contributions}

$X Y, V C$, and $H S$ designed the study. XY, VC, and SL performed the statistical analyses. $X Y, V C$, and $H S$ wrote the manuscript. $E Y, X O$, and JY facilitated the data collection in China. All authors read and approved the final manuscript.

\section{Acknowledgments}

The study was financially supported by Yunnan Provincial Hospital of Traditional Chinese Medicine. The authors would like to thank Edward McNeil for statistical advice and Alan Geater for language correction of the manuscript. The Epidemiology Unit is partially supported by the National Science and Technology Development Agency of Thailand under the Professor Virasakdi Chongsuvivatwong Research Chair grant.

\section{Author details}

'Dermatology Department, Yunnan Provincial Hospital of Traditional Chinese Medicine, Kunming 650011, China. 'Epidemiology Unit, Faculty of Medicine, Prince of Songkla University, Hat Yai, Songkhla 90110, Thailand. ${ }^{3}$ Faculty of Pharmacy, Prince of Songkla University, Hat Yai, Songkhla 90110, Thailand.

Received: 20 September 2012 Accepted: 2 December 2013 Published: 3 January 2014

\section{References}

1. Naldi L: Psoriasis. Dermatol Clin 1995, 13:635-647.

2. Naldi L: Epidemiology of psoriasis. Curr Drug Targets Inflamm Allergy 2004, 3:121-128.

3. Qureshi A, Choi HK, Setty AR, Curhan GC: Psoriasis and the risk of diabetes and hypertension: a prospective study of US female nurses. Arch Dermatol 2009, 145:379-382.

4. Mehta NN, Azfar RS, Shin DB, Neimann AL, Troxel AB, Gelfand JM: Patients with severe psoriasis are at increased risk of cardiovascular mortality: cohort study using the general practice research database. Eur Heart $J$ 2010, 31:1000-1006.

5. Kurd SK, Troxel AB, Crits-Christoph P, Gelfand JM: The risk of depression, anxiety and suicidality in patients with psoriasis: a population-based cohort study. Arch Dermatol 2010, 146:891-895.

6. Zeljko-Penavić J, Situm M, Babić D, Simić D: Analysis of psychopathological traits in psoriatic patients. Psychiatr Danub 2013, 25(Suppl 1):56-59.

7. Grozdev I, Kast D, Cao L, Carlson D, Pujari P, Schmotzer B, Babineau D, Kern E, McCormick T, Cooper KD, Korman NJ: Physical and mental impact of psoriasis severity as measured by the compact short form-12 health survey (SF-12) quality of life tool. J Invest Dermatol 2012, 132:1111-1116.

8. AARDA and NCAPG: The Cost Burden of Autoimmune Disease: The Latest front in the War on Health Care Spending. American Autoimmune Related Diseases Association (AARDA) National Coalition of Autoimmune Patient Groups (NCAPG); 2011. Available online at http://www.diabetesed.net/ page/_files/autoimmune-diseases.pdf.

9. Navarini AA, Laffitte E, Conrad C, Piffaretti P, Brock E, Ruckdaeschel S, Trüeb RM: Estimation of cost-of-illness in patients with psoriasis in Switzerland. Swiss Med Wkly 2010, 140:85-91.

10. Cao YF (Ed): Zhu Bing Yuan Hou Lun. Beijing: People's Medical Publishing House; 1982. In Chinese.

11. Lu DM (Ed): Surgery of Traditional Chinese Medicine. Shanghai: Shanghai Science \& Technique Press; 1997. In Chinese.

12. Zhang G, Wang P, Wang J: Study on the distribution and development rules of TCM syndromes of 2651 psoriasis vulgaris cases. Zhong Yi Za Zhi (J Trad Chin Med) 2008, 49:894-896. In Chinese.

13. Wang $H$, Wang $P$, Zhang G: Change of serum t-lgE and eosinophil cationic protein in 60 patients with psoriasis and analyzing treatment with traditional Chinese medicine. Zhong Guo Zhong Xi Yi Jie He Pi Fu Xing Bing Xue Za Zhi (Chin J Dermatol Venereol of Integ Trad and West Med) 2005 4:153-155. In Chinese.

14. Wu G, Jin J: Research of psoriasis vulgaris classification of traditional Chinese medicine. Ya Tai Chuang Tong Yi Xue (Asia_Pacific Trad Med) 2009, 5:149-150. In Chinese.

15. Li S, Yang Z: Viscera differentiation and treatment of 1000 psoriasis cases in TCM. Shanxi J Trad Chin Med 1998, 19:60-61. In Chinese.

16. Li Z: TCM syndrome differentiation and treatment of psoriasis. Lin Chuang Yi Xue Shi Jian (Proc Clin Med) 2008, 17:693-694. In Chinese.

17. State of Administration of Traditional Chinese Medicine of the People's Republic of China: Criteria of Diagnosis and Therapeutic Effect of Disease and Syndrome Traditional Chinese Medicine. In Traditional Chinese Dermatology. Nanjing: Nanjing University Press; 1994. In Chinese.

18. Yang $X$, Chongsuvivatwong V, McNeil E, Ye J, Ouyang X, Yang E, Sriplung H: Developing a diagnostic checklist of traditional Chinese medicine symptoms and signs for psoriasis: a Delphi study. Chin Med 2013, 8:10. 
19. Henry KL, Muthén B: Multilevel latent class analysis: an application of adolescent smoking typologies with individual and contextual predictors. Struct Equ Modeling 2010, 17:193-215.

20. Swanson SA, Lindenberg K, Bauer S, Crosby RD: A Monte Carlo investigation of factors influencing latent class analysis: an application to eating disorder research. Int J Eat Disord 2012, 45:677-684.

21. Elliott MR, Gallo JJ, Ten Have TR, Bogner HR, Katz IR: Using a Bayesian latent growth curve model to identify trajectories of positive affect and negative events following myocardial infarction. Biostatistics 2005, 6:119-143.

22. Olino TM, Klein DN, Lewinsohn PM, Rohde P, Seeley JR: Latent trajectory classes of depressive and anxiety disorders from adolescence to adulthood: descriptions of classes and associations with risk factors. Compr Psychiatry 2010, 51:224-235.

23. Brown RG, Landau S, Hindle JV, Playfer J, Samuel M, Wilson KC, Hurt CS, Anderson RJ, Carnell J, Dickinson L, Gibson G, van Schaick R, Sellwood K, Thomas BA, Burn DJ: Depression and anxiety related subtypes in Parkinson's disease. J Neurol Neurosurg Psychiatry 2011, 82:803-809.

24. R Foundation: A Language And Environment For Statistical Computing. Vienna, Austria: R Foundation for Statistical Computing; 2011. http://www.R-project.org/.

25. Muthén LK, Muthén BO: Mplus User's Guide. 6th edition. Los Angeles: CA: Muthén \& Muthén; 2010.

26. Zhang NL, Yuan S, Chen T, Wang Y: Latent tree models and diagnosis in traditional Chinese medicine. Artif Intell Med 2008, 42:229-245.

27. Zhang NL: Hierarchical latent class models for cluster analysis. J Machine Learning Res 2004, 5:697-723.

28. Mavandadi S, Nazem S, Ten Have TR, Siderowf AD, Duda JE, Stern MB, Weintraub D: Use of latent variable modeling to delineate psychiatric and cognitive profiles in Parkinson disease. Am J Geriatr Psychiatry 2009, 17:986-995.

29. Jiang YQ: The influence of geographic difference of syndromes differentiation between Southern and Northern in China. Zhong Yi Za Zhi (J Trad Chin Med) 1991, 2:49-51.

30. Sun JJ, Jiang J, Zhu LL, Gao YQ, Yan GL, Su SB: An evaluation method for analysis of correlation between traditional Chinese medicine syndrome and seasonal changes of weather based on information entropy. Zhong Xi Yi Jie He Xue Bao 2007, 5:502-505. In Chinese.

31. Cui N, Xie C, Li A, Wang X, Zhang Q: Clinical research of seasonal distribution regularity of Chinese medicine patterns in acute diarrhea. Shi Jie Zhong Xi Yi Jie He Za Zhi (World J Integ Med) 2011, 6:567-571. In Chinese.

32. Tan J, Han GD, Teng JX, Peng ZP: Epidemiological Survey on TCM syndrome distribution and season correlation of hypertension in Hunan Province [In Chinese]. Zhong Guo Zhong Xi Yi Jie He Za Zhi (Chin J Intetgr Med) 2008, 28(10):897-899.

33. Guo M, Wang P: To Explore the correlation between psoriasis and season in traditional Chinese medicine. Guang Ming Zhoing Yi (Guangming J Chin Med) 2010, 25:2321-2322. In Chinese.

34. Song DY, Chen WW, Sun C, Chen GJ, Wu LL: The influence of geographic difference of irritable bowel syndrome differentiation between Southern and Northern in China. Zhong Yi Za Zhi (J Trad Chin Med) 1991, 1991(2):273-274. In Chinese.

35. Xin J: Different theories and methods for treatment of virus hepatitis by traditional Chinese medicine. Zhong Guo Re Dai Yi Xue (Chin Trop Med) 2002, 2:3. In Chinese

36. Li KL: The research progress of damp-heat in traditional Chinese medicine. Jian Kang Bi Du (J Health) 2012, 2012(1):158-159. In Chinese.

37. Wang YM, Zhang YY, Shao PP, Wang B, Zhou M, Zhang SX: Clinical analysis of psoriatic arthritis and exploration on its syndromes according to pathogenesis. Liaoning Zhong Yi Za Zhi (Liaoning J Trad Chin Med) 2008, 35:1291-1292. In Chinese.

38. Yuan ZZ: The Utility of Integration Traditional Chinese Medicine and Western Medicine in Dermatology. In Psoriasis and Parapsoriasis. Edited by Zhang ZZ. Beijing: Peking Union Medical College Press; 2007. In Chinese.
39. Flaws B, Sionneau P: The Treatment of Modern Western Medical Diseases with Chinese Medicine: A Textbook and Clinical Manual. New Expanded Edition. Corolado: Blue Poppy Press; 2005.

40. Poon MM, Chung KF, Yeung WF, Yau VH, Zhang SP: Classification of insomnia using the traditional Chinese medicine system: a systematic review. Evid Based Complement Alternat Med 2012, 2012:735078.

41. Wiseman N, Feng Y (Eds): A Practical Dictionary of Chinese Medicine. New Mexico: Paradigm Publications; 1998.

doi:10.1186/1749-8546-9-1

Cite this article as: Yang et al:: Identifying the Zheng in psoriatic patients based on latent class analysis of traditional Chinese medicine symptoms and signs. Chinese Medicine 2014 9:1.

\section{Submit your next manuscript to BioMed Central and take full advantage of:}

- Convenient online submission

- Thorough peer review

- No space constraints or color figure charges

- Immediate publication on acceptance

- Inclusion in PubMed, CAS, Scopus and Google Scholar

- Research which is freely available for redistribution

Submit your manuscript at www.biomedcentral.com/submit
C BioMed Central 